\title{
A Qualitative Study Exploring the Needs of Turkish Mothers in the Pediatric Intensive Care Unit
}

\author{
๑ Dilek Beytut1', ๑ Gülçin Özalp Gerçeker2, @ Gonca Karayağız Muslu³ \\ ${ }^{1}$ Girne American University, School of Nursing, Girne, Cyprus \\ ${ }^{2}$ Dokuz Eylül University Faculty of Nursing, Department of Pediatric Nursing, İzmir, Turkey \\ ${ }^{3}$ Muğla Sıtkı Koçman University Fethiye Faculty of Health Sciences, Department of Nursing, Muğla, Turkey
}

\begin{abstract}
Aim: Mothers have different needs, depending on their cultural and religious backgrounds, and these need to be known and acknowledged by the pediatric intensive care unit (PICU) professional staff. To date, limited studies have been conducted in Turkey, a majority Muslim country, which analyzes the needs of mothers whose children are in PICU. The purpose of this study was to explore parents' needs in a child hospital's PICU in Turkey. Materials and Methods: A descriptive exploratory qualitative study. Individual, semi-structured interviews of a purposive sample of 9 mothers were carried out between December 2013 and May 2014. The mothers who were enrolled to participate in the interviews were with an average age of 27.4 years in PICU of a major children's hospital in Turkey.

Results: In the content analysis, the main themes of "being sure of receiving the best care, having needs fulfilled, being able to cope with emotional feelings" were created.

Conclusion: This study presents the disruptions during the PICU process, the fact that it is a difficult process for the mothers and they have many needs during this process and these needs have to be fulfilled.

Keywords: PICU, qualitative, Turkish mother, nursing
\end{abstract}

\section{Introduction}

Being a parent of an infant or a child who has been placed in intensive care is a very difficult experience. Scholars always seek a way to reduce this difficult experience for the families. Included among the causes of stress for families with a child in intensive care are the severity of the disease of the child, the need for mechanical ventilation, the appearance of the child during this period, the concerns of the family regarding the child's future, the appearance of the intensive care unit and its attendant sounds and interventions, the changes in the roles family members must assume and the feelings of uncertainty and despair. In this situation called a family event, most of the parents face psychological negativities
(1-6). Within the last 20 years, in addition to the studies performed that examine the said sources of stress on the families, various studies, involving multidisciplinary teams and a variety of research methods, have been conducted in different cultures and geographic locations that have sought to determine the most important needs of the families in order to obtain universal and predictable data (7). During the critical period, in which the child is in a state of hemodynamic imbalance, the nurses may be under the belief that the needs of the family are matters that should be handled at a later time. However, by determining and fulfilling the needs of the family in the early period, at the time the child is admitted to the intensive care unit, the negative effects of stress can be reduced (7). Meeting needs of parents in accordance with the

\section{Address for Correspondence}

Dilek Beytut PhD, Girne American University, School of Nursing, Girne, Cyprus

Phone: +90 5338438359 E-mail: dilekbeytut@gmail.com ORCID ID: orcid.org/0000-0002-2921-9810

Received: 27.02 .2018 Accepted: 21.05.2018

${ }^{\circ}$ Copyright 2018 by Ege University Faculty of Medicine, Department of Pediatrics and Ege Children's Foundation

The Journal of Pediatric Research, published by Galenos Publishing House. 
principles of the family-centered approach not only provides a trust-based relationship between parents and nurses but also increases parental satisfaction $(1,8,9)$.

According to Ames et al. (10), the needs reported to be most important were "being by the child during his/her care and being involved in the care, having trust in the health professionals and being informed of the course of the child's health condition and treatment", while Al-Mutair et al. (11) found that "disclosure of information, trust, spiritual care, ongoing connection with the patient and involvement in and support for the care" were key. Moreover, in another study, the parents' need of trust was found to be much more important than the need for physical resources or support (12). However, Berube et al. (13) emphasized the need for comfort in the pediatric intensive care unit (PICU) in their study and stated that families were interested in having the security of physical, emotional and psycho-social comfort. Intensive care nurses are health professionals who are in the best possible position to provide support for patients and their families. Nurses provide a sincere and individual care that allows them to develop trust-based relationships with patients and their families, to assess their needs, and to monitor reactions given to changing conditions of the patient by the family members (14). The perception of needs and expectations of the families differ according to ethnical and cultural backgrounds $(15,16)$. According to a systematic compilation by Shudy et al. (17) that reviewed six studies, parents were shown to have needs ranging from being able to communicate with their children, having an understanding about the changes in their condition, having a feeling of hope and being assured that their children are getting the best treatment to being able to maintain the caregiver role, strengthening the family relationship and being provided with accurate information. In the developing country of Turkey, where most of the population is Muslim, one study was conducted that focused on this topic. In this study by Sülü and Başbakkal (18), the spiritual needs of the mother were determined, and other needs, in addition to moral support, such as good care, understanding and provision of information on the health of the child, were cited as being important.

\section{Materials and Methods}

\section{Aim}

This study aimed to conduct an in depth, detailed examination of the needs of mothers whose children were admitted to the PICU.

\section{Study Design and Setting}

To examine these needs, a qualitative research method, using a phenomenological design, was chosen for this study. The purposeful sampling method used to determine the participants resulted in the selection of mothers of nine children who were in the PICU. It was determined that only a small sample group be used, as qualitative studies require that a detailed analysis be made of each case. Inclusion criteria used for participation in the study required that the mother be the primary care provider of a child who had been hospitalized in the PICU for more than 3 days between December 2013 and May 2014 and that the mother agreed to participate in the study, was able to speak and understand Turkish and was older than 18 years of age. The study was conducted in a large district hospital with an intensive care unit containing 24 beds. The 368-bed-capacity hospital has been providing healthcare services in Izmir since 1957. The PICU is composed of three sections. In the first section, which houses children who are in an overall stable condition of health, the children are able to stay with their caregivers. Mothers are involved in their child's care and training and preparation for home care are also performed. All types of intensive care patients, except those with sepsis, are accepted. In the second and third sections, however, constant parent companionship is not permitted. In these sections, according to hospital regulations, parents are only allowed to visit their children two days a week.

\section{Data Collection}

As part of the qualitative research method, the semistructured interview method was used for data collection. The interview form was prepared by examining the relevant literature on the experiences of the families whose children were treated in the PICU (Table I). The interview consisted of five open-ended questions, with the addition of a set of alternative questions available at the end of the interview form. The interviews were conducted on a date and at a time most suitable for the mothers participating in the study, and a private room within the PICU was used to ensure that the interview was carried out in a comfortable manner. Two mothers not involved in the study were interviewed to test the intelligibility of the interview questions and the ease of being able to answer them. The responses of these two mothers were neither recorded nor included in the study. The questions found to be difficult to understand and thereby hard to answer by these two mothers were rephrased before finalizing the interview form. A voice recorder was used, after

Table I. Interview form

1. What do you think about the appearance of the PICU?

-What do you think about the physical features of the PICU?

2. What are your thoughts on the attitude of the health personnel?

3. What are your needs here, from the time your child was first

admitted to the PICU to now?

-What are your physical, emotional and social needs here?

4. How do you feel about the fact that your child is in the PICU?

5. How do you cope with these feelings and thoughts you are experiencing?

PICU: Pediatric intensive care unit 
obtaining prior consent from the mothers, to record the interviews, each of which lasted between 20-50 minutes.

\section{Data Analysis}

The interview data were evaluated using content analysis. To secure the validity and reliability of the research, each interview was transcribed, without the addition of comments. Internal and external reliability was accomplished through strict compliance with the strategies of LeCompte and Goet (19). The transcribed interviews were transferred to a Microsoft Office document and compared with the voice recordings of the interview. Codes were created from interviews that were separately transcribed by two different researchers. The codes created by the researchers were gathered together, out of which the themes formed would serve as the outlines of the study findings (Table II).

Internal homogeneity and external heterogeneity were taken into account as the themes were being created. Particular attention was given to ensuring that the themes were different from each other, the categories and codes of the themes had internal integrity and the themes had integrity with each other. The study sample was determined according to the number of participants it took before reaching data saturation. In other words, as the themes started to repeat and no new codes and themes occurred, the data collection process was finalized.

\section{Ethical Consideration}

Prior to the start of the study, approval to conduct the study was obtained from the İzmir Health Science University Dr. Behçet Uz Child Hospital (approval number: 1339918). Before starting the interview, participants were provided with an explanation of the purpose of the study and were informed that participation was voluntary and that they were free to end the interview at any time. Written and verbal consent was obtained from the mothers who agreed to participate in the study.

\begin{tabular}{|c|c|c|}
\hline Themes & Sub-themes & Codes \\
\hline \multirow{5}{*}{$\begin{array}{l}\text { Certainty of receiving } \\
\text { the best care }\end{array}$} & Perception & $\begin{array}{l}\text { A place where good care is provided to the children and they are attended to, kept in stable } \\
\text { condition and undergo recovery, and where treatments are administered, families cannot enter, } \\
\text { and the setting is clean / Hygienic }\end{array}$ \\
\hline & Hygiene deficiency & $\begin{array}{l}\text { Common areas of use / Air conditioning / Baby food preparation conditions / Materials / } \\
\text { Insufficient barriers at the entrance of PICU }\end{array}$ \\
\hline & $\begin{array}{l}\text { High risk of infection / } \\
\text { Possibility of transmission }\end{array}$ & $\begin{array}{l}\text { Postponement of discharge due to nosocomial infection / Risk of recurrence of disease } \\
\text { Number of patients in the intensive care unit / High number of medical procedures }\end{array}$ \\
\hline & $\begin{array}{l}\text { Attitude of the health } \\
\text { personnel }\end{array}$ & $\begin{array}{l}\text { Good / Helpful / Supportive / Protective / Talkative / Friendly / Caring } \\
\text { Bad / Insecure / Reproving / Not caring / Unequal behavior / Difference in behaviors / Not } \\
\text { smiling / Grumpy / Not Likeable / No empathy }\end{array}$ \\
\hline & Lack of care & $\begin{array}{l}\text { Not giving a bath to the child / Not moisturizing the child's body } \\
\text { Having the care provided by the companions }\end{array}$ \\
\hline \multirow{4}{*}{ Fulfillment of needs } & Being beside the child & Not being able to see the child / Not being able to be together with the child when she cries \\
\hline & Need for information & Not being able to participate in the visits / Curiosity \\
\hline & Need for comfort & $\begin{array}{l}\text { Eating / Sleep / Improper conditions of bath and restroom / improvement / Bath and restroom } \\
\text { in separate places / Not being able to change clothes }\end{array}$ \\
\hline & Family's routine & $\begin{array}{l}\text { Care of other children / Not being able to spare time for the other members of the family / } \\
\text { Quitting job / Argument with the spouse-separation }\end{array}$ \\
\hline \multirow{4}{*}{$\begin{array}{l}\text { Coping with } \\
\text { attendant emotions }\end{array}$} & Feeling & $\begin{array}{l}\text { Trying to feel good / Trying to think that the child will get better / To hope } \\
\text { Uncertainty / Torment / Being tired out / Blaming herself / himself / Despair / Waiting for the } \\
\text { child to die / Being afraid of the death of the child / Pain / Being very miserable / Anxiety / } \\
\text { Sorrow / Anger }\end{array}$ \\
\hline & Religious belief & Pray / Reading the Quran / Taking sanctuary in God / Reciting prayers / Being patient \\
\hline & To distract & $\begin{array}{l}\text { Consoling himself/herself / Trying to stay strong / Showing himself / Herself strong / Smiling } \\
\text { at life / Cheering oneself up / Seeing a psychologist } \\
\text { Dreaming / Spending time on the phone / Walking around / Going to the supermarket }\end{array}$ \\
\hline & Support & $\begin{array}{l}\text { Spouse / Relative / Friend } \\
\text { Insufficiency of the people who will support / Difficulty of coming from another city / Problem } \\
\text { of finding a place to stay }\end{array}$ \\
\hline
\end{tabular}

PICU: Pediatric intensive care unit 


\section{Results}

The average age of the mothers was 27.4 and their educational backgrounds varied between primary school and university graduates. The period of hospitalization of the children in the PICU varied between 5 days and 9 months. For the children, who had been admitted to the PICU as a result of severe medical diagnoses, their age varied between 3 months and 7 years, and 5 of them were males and 4 of them were females (Table III).

According to the content analysis, three main themes were developed: "Certainty of receiving the best care", "fulfillment of needs" and "coping with the attendant emotions" (Table III).

\section{Certainty of Receiving the Best Care}

\section{Perception}

The mothers perceive the PICU as a clean, hygienic place which is clean/hygienic, where good care is provided to the children, children are attended to at all times, children undergo recovery, children are kept in stable health, treatments are administered and families cannot enter. The mothers responded to this question as follows: "Health personnel standing by my child in order to attend to them immediately" [4 Mothers (M)]; "I thought it would be a place we wouldn't be able to enter...a very hygienic place" (7 M); "provide the best care...they are always there to help" (8 M).

\section{Hygiene Deficiency}

Despite believing that the PICU would be clean and hygienic, the mothers did not find the physical environment to actually be hygienic. Most of the mothers mentioned the physical shortcomings of the PICU, describing it as a "dirty place, with beds close to dirty sinks and poor air- conditioning." Others stated, "this place doesn't look like a PICU" and "people should be required to wear overshoes and gloves, but they are not" (9 M).

\section{Risk of Infection}

All of the mothers mentioned the risk of their children acquiring an infection, and most of them stated that their children did indeed get an infection and that their discharge was postponed due to the high number of patients. In particular, they noted, "the first thing I think about is the infection..." (1 M); "my child acquired an infection in the PICU" (2M); "afraid that she will acquire an infection..." and "I want to get out of this hospital as soon as possible" (8 M).

\section{Attitude of the Health Personnel}

The positive and negative statements from the mothers regarding the health personnel included, "they help us...", "they are very warm and friendly and they tend to us..." and "I can talk to the nurses and they always support and take good care of us" (1 M); "I do not look at the monitor screen, so they would comfort us by telling us to not be afraid because nothing was going to happen" (8 M); "...the nurse scolded me..., some of them treated me in a nice manner but others were bad" (5 M); "some were grumpy..., I cannot trust the nurses..., one of them just recently yelled at a mother very badly" (7 M); "she is also a mother like me and therefore would also be hurt if something happened to her child" (8 M).

\section{Lack of Care}

Regarding this issue, the mothers expressed, "our child cannot have a bath..., they have only one wash basin and tub and all of the sick children are washed there" (1 M); "I have been here for 1.5 months and I would not let my child be washed, even if they wanted to because the place is very dirty" (7 M); "there is definitely nothing here in terms of care" (9M).

\begin{tabular}{|l|l|l|l|l|l|}
\hline \multicolumn{6}{|l|}{ Table III. Characteristics of the participants } \\
\hline Participant No. & Age & $\begin{array}{l}\text { Educational } \\
\text { Background }\end{array}$ & $\begin{array}{l}\text { Period/days of } \\
\text { hospitalization in the PICU }\end{array}$ & Age of the child & Diagnosis of the child \\
\hline 1 & 25 & Primary school & 50 & 2 years & Biotinidase deficiency, epilepsy, pulmonary infection \\
\hline 2 & 23 & Middle school & 90 & 11 months & Spinal Muscular Atrophy \\
\hline 3 & 23 & High school & 120 & 1 years & Epilepsy \\
\hline 4 & 38 & University & 620 & 1 years & Spinal Muscular Atrophy \\
\hline 5 & 28 & Primary school & 270 & 7 years & Cerebral Palsy \\
\hline 6 & 24 & Middle school & 7 & 5 months & Ventricular Septal Defect, Atrial Septal Defect, Patent \\
\hline 7 & 25 & High school & 46 & 3.5 months & Epilepsy \\
\hline 8 & 32 & High school & 5 & 3 months & Cardiomegaly \\
\hline 9 & 29 & Primary school & 5 & 7 years & Bronchial Asthma \\
\hline
\end{tabular}

PICU: Pediatric intensive care unit 


\section{Fulfillment of Needs}

\section{Being Beside the Child}

Almost all of the mothers stated that their most basic need was "being beside the child". One of the mothers said "I was so afraid when they told me that I could not stay with my child, but now I am close to my child" (2 M). Another said "I could not see my daughter or have access to her as she cried, but now I am beside her" (5 M).

\section{Need for Comfort}

The mothers felt that PICU was extremely uncomfortable and expressed problems involving food, sleeping, bathing, restroom and changing clothes. The mothers explained their discomfort about this matter as follows; "I had to eat next to my child. I wish there was a separate room and no smell of food...", (4 M); "it would be nice if the restroom and sink were separate...", "it is disgusting...", "you cannot take a bath or change your clothes" (5 M); "I am not happy with the place I am sleeping", "both of my sides are hurting, but I will put up with everything for the sake of my child" (6 M).

\section{Need for Information}

One of the most important needs of the mothers is the provision of information. The mothers expressed their concerns on this matter as follows: "When they perform visits, they remove us from the room, do not directly tell you that she could die or that we could lose her" (8 M); "information should be provided right after the visit, but no information was provided" (9 M).

\section{Family's Routine}

The mothers stated, in the following expressions, that their family routines were disrupted: "I have another son and he needs me a lot, but I cannot take care of him." (1 M); "my husband quit his job and came here, like me"..., "we suffered disappointment, and now our family life has been disrupted" (4 M); "my husband and I argue from time to time"..., "until this time, I had not been separated from my husband like this" (6 M).

\section{Coping with Attendant Emotions}

\section{Feelings}

One of the mothers expressed her feelings regarding having her child in the PICU as follows: "I tell myself that my child is going to be fine" (6 M); "most of the mothers have negative feelings...", "uncertainty, this makes me very sad" (3 M); "I blame myself. I did not take care of him well. If I had, he would not be sick. I am guilty" (9 M); "despair...waiting for my child to die" (2M); "my world has crashed down around me...I am still sad and worried..." (8 M).

\section{Religious Belief}

These responses constitute themes of religious belief, support and distraction. "God is my helper. I pray and read the Qur'an" (4 M); "I pray to God and recite prayers; try to be patient" (7 M).

\section{To Distract}

Here are some statements from mothers who coped with their negative emotions using methods outside of religious beliefs: "This psychologically affects me a lot. I try to stand, ...I have people who need me and therefore, I want to be strong" (1 M); "by smiling, I try to keep living my life, talking about my problems, it makes me feel good, it cheers me up, s/he says don't be sad, s/he is going to live with the help of God, s/he supported me a lot, I can cope due to all this support" (6 M); "if you tell your loved ones, they will be sad...my sleep helps me. I see my child standing and smiling, it will be fine, I see things like this and it makes me feel better" (4 M).

\section{Support}

Most of the mothers expressed that they receive support from their spouses, relatives and friends in the following manner: "I can share it with my husband, my closest relatives, I do not like sharing it with the other moms because their psychology is not good" $(1 \mathrm{M})$; "there were our friends whom we met here, their child was discharged, so we talk on the phone" ( $3 \mathrm{M})$; the mothers stay as companions of all patients in the PICU. The mothers also talked about the difficulty of the situation, saying the following: "I do not have any relatives here, so I cannot leave my child and go. I am always here" (4 M); "my husband cannot stay as there is no place for him to sleep here, and it is very far away, so he comes in the mornings and goes back in the evenings" (7 M).

\section{Discussion}

The findings obtained from the study were discussed within the context of three main themes:

\section{Certainty of Receiving the Best Care}

In the intensive care unit where the study was conducted, as the children and the mothers share the room, the mothers were able to closely witness all of the behavior, positive and negative, directed towards their children. Therefore, the mothers' perception of the intensive care environment was largely affected by this situation. In a study by Latour et al. (20), parents whose child was alone in the room describe the environment as peaceful, quiet and private. Diaz-Caneja et al. (21), in their study, described parents as "tubes surrounding their children" and focused on physical features. They mentioned that while many of the healthcare professionals made the parents feel secure, the appearance of the children was a matter of concern worrying for the parents.

In our study, the mothers voiced positive and negative thoughts on the attitudes of the healthcare personnel. In 
order to replace negative perceptions with positive ones, the PICU nurses should develop greater awareness of this matter and review their approach to the families. The data from the study by Hall (22) showed that some families stated that the nurses were "kind, helpful, informative, and capable", while others complained that they were "the sole agency of care, ignorant, distressed and worried-looking". Our study, on the other hand, found that some of mothers expressed the positive aspects of the healthcare personnel, such as their supportiveness, willingness to talk and consideration. In the PICU (24-bed capacity) where the study was conducted, ten nurses work the day-shift and nine nurses work the nightshift. The patient/nurse ratio is approximately $2: 4$, and the tense, tiring working environment contributes to the nurses' failure to adopt a more patient oriented approach, keeping them stuck in a job oriented style of working. This situation explains why they sometimes have difficulties using efficient communication techniques when talking with mothers.

Another matter brought up by the families in our study was the lack of care. This is a particularly key point, as quality of care is one of the most important issues for families (23). Latour et al. (20) discussed family care coordination, suggesting that participation in the child's care is an important matter; however, this request should depend on the family - whether or not they feel ready - and the burden of care should not be completely on the family. Mattsson et al. (24) defined the meaning of care in the PICU as "building a sheltered atmosphere, meeting the child's needs and adapting the environment to family life". When a child is admitted to the PICU, the life of the family changes and they may feel like they have lost a part of their responsibilities (5). As they are accustomed to fulfilling all of the needs of their children at home, a disconnection between roles may occur as a result of the fulfillment of these needs being taken on by the healthcare personnel in the PICU (25).

\section{Fulfillment of Needs}

A majority of the mothers stated that their most basic need was "being beside the child". In the study by McKiernan and McCarthy (26), it was found that the primary source of stress for family members was not being able to see their children. In the PICU of our study, the mothers were allowed to be close to their children, and they were taken out of the room only in the event something unexpected occurred and during doctor or nurse visits. It is essential that the doctors and nurses talk to the families at the end of the visit and inform them of the child's prognosis. Almost all studies mention that the patient's relatives need sufficient and accurate information $(11,13,23)$.

The mothers stated that the PICU was extremely uncomfortable and cited problems relating to food, sleeping, bathing, the restrooms and changing clothes. The basic needs in the PICU, in terms of the familial need hierarchy, are physiological needs, such as sleeping and eating. The possibility of families getting involved in their child's care, providing social support, and most difficult of all, fulfilling their emotional needs, is greatly diminished when the physiological needs are not first fulfilled (13). Majdalani et al. (23) and Berube et al. (13) stated that, as families were in search of comfort, the PICU should be organized in such a way as to provide comfort to and meet the physical needs of the families.

Another matter that has a negative impact on family life during the PICU process is the disruption of the family's routine. Lam et al. (27) noted the impact of "rescheduling of family routine" on the involvement of the families in the child's care, while Mattsson et al. (24) mentioned the importance of "adapting the environment for family life". In our study, as stated before, the mothers of the children stayed with them. Therefore, most of them had to quit their jobs and ask their relatives to take care of their other children. The job-centered style of working that nurses practice results in neglect shown to the parents. The nurses responsible for caring for the children in the PICU should be facilitators in ensuring that all of the family members involved in the care of the child are in a position to provide social support to the mothers, in creating resting periods and in enabling them to have some time for themselves.

\section{Being Able to Cope with Feelings}

If the healthcare professionals are aware of the feelings experienced by the families, they will be better able to deal with them. Latour et al. (20) highlighted the idea of "intensity" and stated that the families have negative feelings about the PICU. The study by Hall (22) revealed that the PICU reminds people of death. Among the ways for dealing with their emotions, the most commonly expressed tool was religious belief. This result was not surprising in Turkey, as the country is predominantly Muslim. Majdalani et al. (23) cited "Dependence on God" and Al-Mutair et al. (11) "Faith in God, reading of the Qur'an, prayer and charity" as coping mechanisms in their studies. Many of the mothers stated that they received support from their husbands, relatives and friends. Berube et al. (13) and McKiernan and McCarthy (26) noted that the families needed support for dealing with the situation. The Islam-inspired fatalistic approach served as another coping mechanism. It is a common belief to take the negative situations for granted, as they are done at the discretion of God. With this understanding, God shall redeem his people from their sins in return for all the hardships they experienced; therefore, when rough times come upon them, then it is surely because God loves them.

\section{Ethics}

Ethics Committee Approval: The study was approved by the Izmir Health Science University Dr. Behçet Uz Child Hospital (approval number: 1339918). 
Informed Consent: Consent form was filled out by all participants.

Peer-review: Externally and internally peer-reviewed.

\section{Authorship Contributions}

Concept: D.B., G.Ö.G., Design: D.B., G.Ö.G., G.K.M., Data Collection or Processing: D.B., Analysis or Interpretation: D.B., G.Ö.G., Literature Search: D.B., G.Ö.G., G.K.M., Writing: D.B., G.Ö.G.

Conflict of Interest: No conflict of interest was declared by the authors.

Financial Disclosure: The authors declared that this study received no financial support.

\section{References}

1. Vasli P, Dehghan-Nayeri N, Borim-Nezhad L, Vedadhir A Dominance of paternalism on family-centered care in the Pediatric Intensive Care Unit (PICU): An ethnographic study. Issues Compr Pediatr Nurs 2015;38:118-35.

2. Colville G, Darkins J, Hesketh J, Bennett V, Alcock J, Noyes J. The impact on parents of a child's admission to intensive care: integration of qualitative findings from a cross-sectional study. Intensive Crit Care Nurs 2009;25:72-9.

3. Needle JS, O'Riordan M, Smith PG. Parental anxiety and medical comprehension within 24 hrs of a child's admission to the pediatric intensive care unit. Pediatr Crit Care Med 2009;10:66874.

4. Jee RA, Shepherd JR, Boyles CE, Marsh MJ, Thomas PW, Ross OC. Evaluation and comparison of parental needs, stressors, and coping strategies in a pediatric intensive care unit. Pediatr Crit Care Med 2012;13:166-72.

5. Mcdonald ME, Liben S, Carnevale FA, Cohen SR. An Office or a bedroom? Challenges for family-centered care in the pediatric intensive care unit. I Child Health Care 2012;16:237-49.

6. Delva D, Vanoost S, Bijttebier P, Lauwers P, Wilmer A. Needs and feelings of anxiety of relatives of patients hospitalized in intensive care units: implications for social work. Soc Work Health Care 2002;35:21-40.

7. Meert KL, Briller SH, Schim SM, Thurston CS. Exploring parents' environmental needs at the time of a child's death in the Pediatric intensive care unit. Pediatr Crit Care MeD 2008;9:6238.

8. Ladak LA, Premji SS, Amanullah MM, Haque A, Ajani K, Siddiqui F). Family centered rounds in Pakistani pediatric intensive care settings: non-randomized pre- and post-study design. Int / Nurs Stud 2013;50:717-26.

9. Butler A, Copnell B, Willets G. Family-centred care in the paediatric intensive care unit: an integrative review of the literature. J Clin Nurs 2014;23:2086-100.

10. Ames KE, Rennick JE, Baillargeon S. A qualitative interpretive study exploring parents' perception of the parental role in the paediatric intensive care unit. Intens Crit Care Nurs 2011;27:14350.
11. Al-Mutair AS, Plummer V, Clerehan R, O'Brien A. Needs and experiences of intensive care patients' families: a Saudi qualitative study. Nurs Crit Care 2014;19:135-44.

12. Meert KL, Schim S, Briller S. Parental bereavement needs in the pediatric intensive care unit: review of available measures. I Palliative Med 2011;14:951-64.

13. Berube KM, Fothergill-Bourbonnais F, Thomas M, Moreau D. Parents' Experience of the Transition with their Child from a Pediatric Intensive Care Unit (PICU) to the Hospital Ward: Searching for Comfort Across Transitions. I Pediatr Nurs 2014;29:586-95.

14. Adams JA, Anderson RA, Docherty SL, Tulsky JA, Steinhauser KE, Bailey DE Jr. Nursing Strategies to Support Family Members of ICU Patients at High Risk of Dying. Heart Lung 2014;43:406-15.

15. Hall EO. Being in an alien world: Danish parents' lived experiences when a newborn or small child is critically ill. Scand J Caring Sciences 2005;19:179-85.

16. Tseng Y, Verklan T. Fathers in situational crisis: a comparison of Asian and Western cultures. Nurs Health Sci 2008;10:229-40.

17. Shudy M, de Almeida ML, Ly S, et al. Impact of pediatric illness and injury on families: a systematic literature review. Pediatrics 2006;118(Suppl 3):203-18.

18. Sülü E, Başbakkal Z. Yoğun bakımda yatan çocuk hastaların annelerinin manevi bakım (Spiritüel Bakım) gereksinimleri (Spiritual care requirements of the mothers of the hospitalized children in intensive care units). J Turk Soc Intens Care 2013;11:1724.

19. LeCompte MD, Goet JP. Problems of reliability and validity in etnographic research. Rev Educ Res 1982;52:31-60.

20. Latour JM, van Goudoever JB, Schuurman BE, et al. A qualitative study exploring the experiences of parents of children admitted to seven Dutch pediatric intensive care units. Intens Care Med 2011;37:319-25.

21. Diaz-Caneja A, Gledhill I, Weaver T, Nadel S, Garralda E. A child's admission to hospital: a qualitative study examining the experiences of parents. Intensive Care Med 2005;31:1248-54.

22. Hall EO. Danish parents' experiences when their new born or critically ill small child is transferred to the PICU-a qualitative study. Nurs Crit Care 2005;10:90-7.

23. Majdalani MN, Doumit MA, Rahi AC et al. The lived experience of parents of children admitted to the pediatric intensive care unit in Lebanon. Int I Nurs Stud 2014;51:217-25.

24. Mattsson JY, Arman M, Castren M, Forsner M. Meaning of caring in pediatric intensive care unit from the perspective of parents: A qualitative study. I Child Health Care 2014;18:336-45.

25. Graham RJ, Pemstein DM, Curley MA. Experiencing the pediatric intensive care unit: Perspective from parents of children with severe antecedent disabilities. Crit Care Med 2009;37:2064-70.

26. McKiernan M, McCarthy G. Family members' lived experience in the intensive care unit: a phemenological study. Intens Crit Care Nurs 2010;26:254-61.

27. Lam LW, Chang AM, Morrissey J. Parents' experiences of participation in the care of hospitalised children: a qualitative study. Int J Nurs Stud 2006;43:535-45. 